\title{
The contribution of LARGE genomic rearrangements of BRCA1 and BRCA2 gene mutations in breast and ovarian cancer families in a clinical cohort
}

S Sawyer ${ }^{1 *}$, S Boyle², MA Young ${ }^{1}$, S Kovalenko², R Doherty ${ }^{1}$, J McKinley ${ }^{1}$, K Alsop $^{1}$, M Rehfisch², S Macaskill ${ }^{2}$, A Ha $^{2}$,

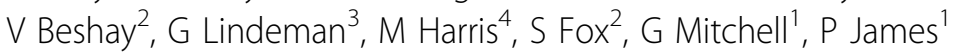

From Familial Aspects of Cancer 2011 Research and Practice: A combined meeting of kConFab, Australian Breast Cancer Family Study, Australian Colorectal Cancer Family Study, Australian Ovarian Cancer Study, Family Cancer Clinics of Australia and New Zealand and kConFab

Kingscliff, Australia. 23-26 August 2011

\section{Background}

The use of multiplex ligation-dependent probe amplification (MLPA) to detect large scale rearrangements is now a standard component of BRCA1 and BRCA2 gene testing in the clinical setting. With the cost of full Sanger sequencing up to 4 times higher than the cost of MLPA, it is important not only to determine the prevalence of these mutations but to ascertain the probability that a family may harbour a large deletion or rearrangement in the BRCA1 and BRCA2 genes. Here we examine the incidence and clinical associations of genomic rearrangements in the BRCA1 and BRCA2 genes in a cohort of index cases from high risk breast and ovarian cancer families recruited from familial cancer centres (FCC).

\section{Method and results}

The Victorian FCC Translational breast cancer cohort includes 1222 index cases identified from families who had been seen through one of the four FCCs in Victoria. Until 2007, standard BRCA tests did not include MLPA but instead used a variety of sequencing-based methods which included PTT, DHPLC and Sanger sequencing. Of these cases, 246 (20.1\%) were found to carry a $B R C A 1$ or $B R C A 2$ mutation using sequencing-based methods. In a small proportion of cases MLPA was performed prior to study commencement based on clinical indications leading to the detection of 11 mutations. A

${ }^{1}$ Peter MacCallum Cancer Centre: Familial Cancer Centre, Australia Full list of author information is available at the end of the article total of 965 cases were found not to carry a BRCA1 or $B R C A 2$ mutation through sequencing-based methods and were eligible for MLPA in the study. A hundred and nine cases were excluded from testing: 19 did not fit inclusion criteria, 93 had unsuitable DNA for testing.

In the remaining 856 cases a further 24 (2.8\% of cases) $B R C A 1$ and BRCA2 mutations were identified using MLPA. In the total cohort of 1113 index cases, 246 (22.1\%) BRCA1 and BRCA2 mutations have been identified, including 36 (14.2\% of mutations) large deletions and duplications detected through MLPA. Mean age of onset for first breast cancer diagnosis was 41 years (2673) in mutation carriers detected using sequencing based methods and 40 years (18-60) in cases with genomic rearrangements detected by MLPA.

Analysis of the BRCAPRO scores revealed that the mean BRCA carrier probabilities for BRCA mutation carriers detected though MLPA were significantly higher than those detected using sequencing based methods ( 0.58 versus 0.37 respectively, $\mathrm{p}=0.002)$. Further analysis of correlations between mutation type and patient demographics including the cancer profile of the index case and their $1^{\text {st }}-3^{\text {rd }}$ degree family members, rates of bilateral breast cancer, male breast cancer and early age of onset will be presented.

\section{Conclusion}

MLPA detected genomic rearrangements accounted for $14 \%$ of all BRCA mutations in a large cohort of Victorian 
FCC families. The association with higher pre-test carrier probabilities indicates that an optimal strategy for BRCA mutation detection in which an initial MLPA screen in high risk families may avoid the need for sequencing in some patients where a genomic rearrangement is present, with an associated cost saving.

\section{Author details}

${ }^{1}$ Peter MacCallum Cancer Centre: Familial Cancer Centre, Australia. ${ }^{2}$ Peter MacCallum Cancer Centre: Molecular Pathology Laboratory, Australia. ${ }^{3}$ Royal Melbourne Hospital: Familial Cancer Centre, Australia. ${ }^{4}$ Monash Medical Centre: Familial Cancer Centre, Australia.

Published: 12 April 2012

doi:10.1186/1897-4287-10-S2-A89

Cite this article as: Sawyer et al:: The contribution of LARGE genomic rearrangements of BRCA1 and BRCA2 gene mutations in breast and ovarian cancer families in a clinical cohort. Hereditary Cancer in Clinical Practice 2012 10(Suppl 2):A89.

Submit your next manuscript to BioMed Central and take full advantage of:

- Convenient online submission

- Thorough peer review

- No space constraints or color figure charges

- Immediate publication on acceptance

- Inclusion in PubMed, CAS, Scopus and Google Scholar

- Research which is freely available for redistribution

Submit your manuscript at www.biomedcentral.com/submit 